\title{
Leucemia linfoide aguda em gatos infectados pelo vírus da leucemia felina com diagnóstico presuntivo de 12 casos
}

\author{
Acute lymphoid leukemia in cats infected by the feline leukemia virus with \\ assumption diagnosis of 12 cases
}

\author{
Polyana Pulcheira Paixão ${ }^{1}$; Marcus Vinicius Sandoval Paixão ${ }^{2 *}$, Fernanda de Oliveira \\ Silvestre ${ }^{1}$, Rodrigo dos Santos Horta ${ }^{1}$
}

\begin{abstract}
RESUMO
A leucemia é definida como uma neoplasia de células hematopoiéticas. Pode ser classificada em quadros agudos ou crônicos, sendo o vírus da FeLV intimamente ligado a causa de leucemias agudas. Em caráter retrospectivo, nove animais diagnosticados FeLV positivos, com a evidenciação de bicitopenia, associada ao predomínio de linfócitos (superior a $80 \%$ ) foram selecionados para uma análise hematológica. Todos os animais apresentaram linfocitose acentuada (> 13.000 céls $/ \mu \mathrm{L}$ ) e em apenas dois gatos foram encontrados linfoblastos. O protocolo quimioterápico Wisconsin-Madison modificado foi realizado em quatro gatos, mas somente o gato 7 sobreviveu e obteve melhora do quadro clínico. Os nove gatos avaliados neste trabalho apresentaram características compatíveis com um quadro leucêmico agudo, tendo uma sobrevida de 16 dias, o que indica ser uma enfermidade de curso rápido e prognóstico ruim, dificultando a realização de exames mais complexos para um diagnóstico definitivo.
\end{abstract}

Palavras chave: Neoplasia, Felinos, linfoblastos.

\section{ABSTRACT}

Leukemia is defined as a hematopoietic cell neoplasm. It can be classified into acute or chronic conditions, with the FeLV virus being closely linked to the cause of acute leukemias. Retrospectively, nine animals diagnosed as FeLV positive, with evidence of bicytopenia, associated with a predominance of lymphocytes (greater than $80 \%$ ) were selected for hematological analysis. All animals showed marked lymphocytosis (> 13,000 cells $/ \mu \mathrm{L}$ ) and lymphoblasts were found in only two cats. The modified Wisconsin-Madison chemotherapy protocol was performed in four cats, but only cat 7 survived and had an improvement in the clinical picture. The nine cats evaluated in this study presented characteristics compatible with an acute leukemic condition, with a survival of 16 days, which indicates that it is a disease with a rapid course and poor prognosis, making it difficult to carry out more complex tests for a definitive diagnosis.

Index terms: Neoplasm, Cats, lymphoblasts.

\footnotetext{
${ }^{1}$ Instituto Federal do Espírito Santo

*E-mail: mvspaixao@gmail.com

${ }^{2}$ Climev Vitória
} 


\section{INTRODUÇÃO}

O Vírus da Leucemia Felina (FeLV) foi descrito pela primeira vez por Jarret et al. (1964) após a detecção de partículas virais ligadas à membrana de linfoblastos em um gato com linfoma. O vírus foi classificado em quatro subgrupos (FeLV-A, B, C e T) com base na sua capacidade de replicação nos tecidos, sendo o FeLV-A o único contagioso. O vírus está presente na saliva de gatos infectados e pode ser transmitido por contato direto, principalmente por hábitos de higiene entre os animais, como lambedura dos pelos. Também pode ocorrer por compartilhamento de vasilhas de água e comida (LEVY et al., 2008). Outras formas de infecção menos comuns incluem a transmissão transplacentária e transmamária, mas também pelas lágrimas, sangue, urina, fezes e fômites (LUTZ et al., 2009).

O FeLV pertence à família Retroviridae, uma vez que seu genoma é constituído por um RNA de fita simples, mas pode gerar uma fita dupla de DNA, capaz de se inserir no genoma da célula hospedeira, de forma estável, momento no qual, os genes virais se comportam como genes celulares e podem ser transcritos em produtos proteicos funcionais, ou permanecer latente por um longo período de tempo. Os gatos que se tornarem persistentemente virêmicos podem ser assintomáticos ou desenvolver imunossupressão, alterações hematológicas, distúrbios intestinais ou reprodutivos, neoplasias como linfoma e leucemia, e doenças imunomediadas, caracterizando diferentes manifestações clínicas (CARMICHAEL et al., 2002).

A leucemia é definida como uma proliferação neoplásica de células hematopoiéticas classificada com base na morfologia celular em crônica ou aguda, sendo a crônica caracterizada pela proliferação de células maduras, bem diferenciadas, normalmente não associada ao FeLV (TEBB et al., 2004). Entretanto, na leucemia aguda, a medula óssea é tomada por células imaturas (blásticas) (DOBSON et al., 2006) e a hematopoese normal é suprimida, cursando com trombocitopenia e/ou anemia, e sinais clínicos como letargia, hepatoesplenomegalia, devido a hematopoiese extramedular ou infiltração maligna, e icterícia. Em alguns casos, a proliferação neoplásica se inicia no baço e o envolvimento da medula óssea ocorre tardiamente no curso da doença. A leucemia pode ser classificada com base na linhagem celular em mieloide e linfoide, sendo aquelas de origem linfoide, mais frequentes (HARTMANN, 2015; WELLMAN, 2015). 
A leucemia linfóide crônica ou linfocítica (LLC) é incomum e raramente documentada em gatos domésticos. Quando o animal desenvolve o quadro leucêmico, observa-se proliferação de linfócitos bem diferenciados na medula óssea, podendo circular pelo sangue periférico ou acometer outros órgãos. As manifestações clínicas incluem perda de peso, hiporexia a anorexia, letargia, vômitos, diarreia, entre outros. Ao exame clínico, alguns gatos podem apresentar linfadenomegalia, principalmente em linfonodos inguinais e poplíteos (CAMPBELL et al., 2012). O número de linfócitos circulantes em gatos com LLC geralmente é alto e muitas vezes acompanhado por porcentagens de linfócitos na medula óssea que excedem 15 a $20 \%$ do total de células nucleadas (WORKMAN et al., 2004; CAMPBELL et al., 2012).

A leucemia linfoide aguda ou linfoblástica (LLA), por sua vez, é a mais frequente dentre as leucemias. Apresenta comportamento biológico agressivo, e sua malignidade pode ser evidenciada através da morfologia celular e curso clínico rápido e fatal (AVERY \& AVERY, 2007). Acomete gatos de idade variável, sendo caracterizada pelo aumento moderado à acentuado dos linfonodos, anemia, neutropenia e trombocitopenia, pela destruição dos precursores medulares, podendo haver ou não linfocitose, e ainda reatividade de linfócitos, linfoblastos e atipias celulares na avaliação do esfregaço periférico (WELLMAN, 2015; DOBSON et al, 2006).

O tratamento é estabelecido de acordo com o quadro clínico e suas manifestações, tendo como objetivo destruir as células neoplásicas. Os protocolos utilizados para o tratamento de linfomas são os mesmos realizados em animais com LLA e LLC (CAMPBELL et al., 2012; BOUZOURAA et al., 2018). O uso de quimioterápicos é limitado em casos de anemia, trombocitopenia e neutropenia. A incapacidade de preservar níveis suficientes de células sanguíneas normais é uma consequência comum nesses animais em tratamento (TASCA et al., 2009). Além disso, as toxicidades desses fármacos podem comprometer a função renal e hepática. A maioria dos pacientes desenvolvem sepse secundária a neutropenia, e/ou falência de órgãos secundária a infiltração leucêmica e coagulação intravascular disseminada (CID) (DOBSON et al., 2006).

A LLC freqüentemente resulta em uma expectativa de vida superior a dois anos, entretanto, o prognóstico para a LLA é considerado desfavorável, devido á baixa resposta aos tratamentos e rápida progressão da doença, com uma expectativa de vida apenas de dias a semanas (DOBSON et al., 2006; WELLMAN, 2015). 
O trabalho foi realizado com o objetivo de relatar o diagnóstico presuntivo e as alterações laboratoriais em nove gatos com LLA associada ao FeLV, visando favorecer o reconhecimento dessa patologia e a instituição precoce do tratamento.

\section{MATERIAL E MÉTODOS}

Em caráter retrospectivo foram revisados os prontuários médicos de nove gatos diagnosticados com LLA, associada ao FeLV, no Hospital Veterinário Prof. Ricardo Alexandre Hippler da Universidade Vila Velha, Espírito Santo, e incluso mais três casos atendidos recentemente no período de setembro de 2015 a fevereiro de 2020. O diagnóstico foi estabelecido pela evidenciação de bicitopenia, associada ao predomínio de linfócitos (superior a 80\%), e confirmação da infecção progressiva pelo FeLV por meio do teste de imunoensaio rápido SNAP FIV/FeLV Combo Idexx, em amostras de sangue, após separação do soro. Os dados referentes a resultados de eritograma, plaquetograma, leucograma e bioquímica sérica foram planilhados no software Excel 365 (2016) e submetidos a análise descritiva. A sobrevida foi estimada pela curva de Kaplan-Meier, no software Graph Pad Prism v.6.02

\section{RESULTADOS E DISCUSSÃO}

Dos doze felinos avaliados, oito eram fêmeas e quartro machos, sendo quatro fêmeas castradas e um macho castrado. Dentre as raças, dois eram siameses, um persa e nove não possuíam raça definida. Apresentaram idade de 2 a 8 anos (4,2 22,0 anos) e o peso variou de 1,6 a $4,8 \mathrm{~kg}(3,6 \pm 1,0 \mathrm{~kg})$.

Os resultados do eritrograma, no momento do diagnóstico, encontram-se demonstrados na Tabela 1. Evidenciou-se anemia em sete gatos, sendo normocítica normocrômica $(n=2)$ e macrocítica hipocrômica $(n=4)$. Anemia normocítica hipercrômica, no gato de número 3, foi atribuída à hemólise da amostra. Em relação a contagem de plaquetas, 11/12 apresentaram trombocitopenia. 
Tabela 1 - Eritograma e plaquetograma no momento do diagnóstico da leucemia linfóide aguda em nove gatos

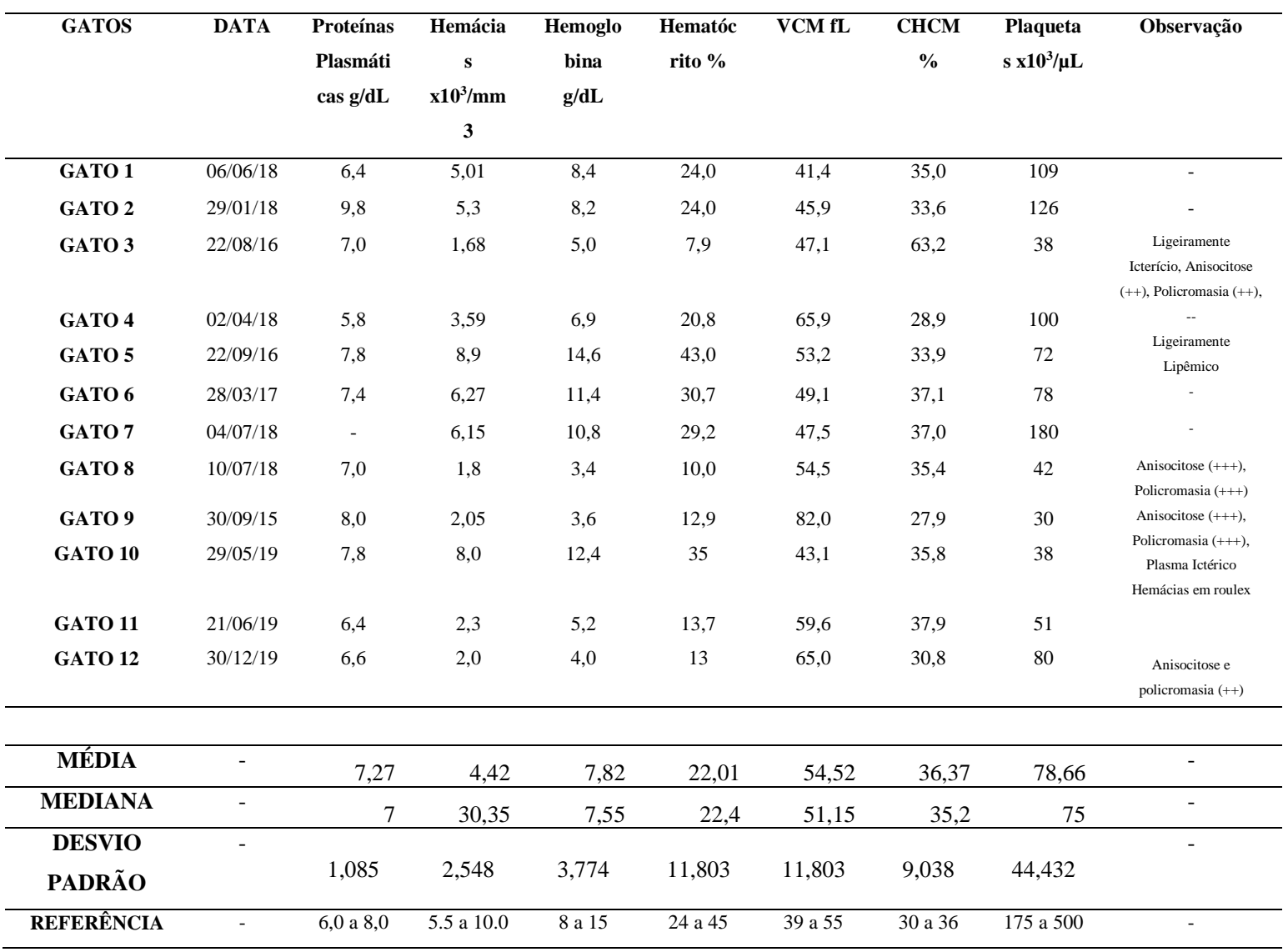

De acordo com os leucogramas demonstrados na Tabela 2, observou-se linfocitose em todos os gatos, mas um deles não apresentou leucocitose global, devido à intensa neutropenia. Oito gatos apresentaram linfocitose superior a 40.000 céls/ $\mu \mathrm{L}$ e dez, acima de 20.000 céls $/ \mu \mathrm{L}$. Neutropenia foi observada em quatro gatos, enquanto apenas um apresentou neutrofilia, com desvio à esquerda, mas ainda regenerativo. Monocitose foi identificada em apenas um gato. Seis gatos apresentaram contagem total de leucócitos superior a $100.000 / \mu \mathrm{L}$ e três destes apresentaram, ainda, linfoblastos, no sangue periférico. Essas células apresentam-se com diâmetro 3x maior do que de uma hemácia, citoplasma moderado, azulado, com halo claro perinuclear, núcleo redondo, cromatina pontilhada e um a dois nucléolos distintos (Figura 1). Na bioquímica detectou-se hipoalbuminemia em dois gatos e hiperalbuminemia em um paciente. Dois gatos apresentaram ainda elevação dos valores de ALT e AST. 
Tabela 2 - Leucograma no momento do diagnóstico da leucemia linfóide aguda em nove gatos

\begin{tabular}{|c|c|c|c|c|c|c|c|c|c|c|}
\hline GATOS & DATA & $\begin{array}{l}\text { Leucócitos } \\
/ \mu \mathrm{L}\end{array}$ & $\begin{array}{c}\text { Bastone } \\
\text { tes/ } \mu \mathrm{L}\end{array}$ & $\begin{array}{c}\text { Segmenta } \\
\operatorname{dos} / \mu \mathrm{L}\end{array}$ & $\begin{array}{c}\text { Linfócitos } \\
/ \mu \mathrm{L}\end{array}$ & $\begin{array}{c}\text { Monócit } \\
\text { os } / \mu \mathrm{L}\end{array}$ & $\begin{array}{c}\text { Eosinófi } \\
\operatorname{los} / \mu \mathrm{L}\end{array}$ & $\begin{array}{c}\text { Basófilo } \\
\mathrm{s} / \mu \mathrm{L}\end{array}$ & $\begin{array}{c}\text { Metami } \\
\text { elócitos/ } \\
\mu \mathrm{L}\end{array}$ & Observações \\
\hline GATO 1 & $06 / 06 / 18$ & 14.500 & 0 & 870 & 13.630 & 0 & 0 & 0 & 0 & -- \\
\hline GATO 2 & $29 / 01 / 18$ & 145.600 & 0 & 8736 & 135.408 & 1456 & 0 & 0 & 0 & Linfoblastos (+) \\
\hline GATO 3 & $22 / 08 / 16$ & 228.900 & 0 & 4578 & 224.322 & 0 & 0 & 0 & 0 & Linfoblastos (+++) \\
\hline GATO 4 & $02 / 04 / 18$ & 43.300 & 0 & 2598 & 40.269 & 0 & 433 & 0 & 0 & - \\
\hline GATO 5 & $22 / 09 / 16$ & 22.200 & 0 & 3996 & 17.760 & 0 & 444 & 0 & 0 & - \\
\hline GATO 6 & $28 / 03 / 17$ & 38.800 & 0 & 6208 & 32.592 & 0 & 0 & 0 & 0 & $\begin{array}{c}\text { Linfócitos reativos } \\
\qquad(++)\end{array}$ \\
\hline GATO 7 & $04 / 07 / 18$ & 125.500 & 0 & 2510 & 119.225 & 2510 & 1255 & 0 & 0 & Linfoblastos (++) \\
\hline GATO 8 & $10 / 07 / 18$ & 23.474 & 0 & 234,7 & $23.239,3$ & 0 & 0 & 0 & 0 & $\begin{array}{c}\text { Linfócitos reativos } \\
(+)\end{array}$ \\
\hline GATO 9 & $30 / 09 / 15$ & 73.400 & 1468 & 12478 & 57.986 & 0 & 734 & 0 & 734 & $\begin{array}{c}\text { Linfócitos reativos } \\
\qquad(+)\end{array}$ \\
\hline GATO 10 & $29 / 05 / 19$ & 116.100 & 0 & 3483 & 111.456 & 1101 & 0 & 0 & 0 & $\begin{array}{l}\text { Linfócitos reativos } \\
(++) \text { Linfócitos } \\
\text { atípicos (+) manchas } \\
\text { de Gumprecht } \\
\text { Linfócitos reativos }\end{array}$ \\
\hline GATO 11 & $21 / 06 / 19$ & 101.100 & 0 & 3888 & 66.104 & 0 & 0 & 0 & 0 & $(+++)$ \\
\hline GATO 12 & $30 / 12 / 19$ & 150.000 & 0 & 4500 & 144.000 & 0 & 1.500 & 0 & 0 & $\begin{array}{l}\text { Linfócitos reativos } \\
(++) \text { linfócitos } \\
\text { atípicos (++) }\end{array}$ \\
\hline MÉDIA & -- & 83.177 & 146,8 & 4569,17 & 77.589 & 506,7 & 286,6 & 0 & 83.177 & - \\
\hline MEDIANA & -- & 58.350 & 0 & 3739,5 & 49.128 & 0 & 0 & 0 & 0 & - \\
\hline $\begin{array}{l}\text { DESVIO } \\
\text { PADRÃO }\end{array}$ & -- & 69650,90 & 464,22 & 3722,35 & 885,98 & 885,98 & 431,66 & 0 & 69650,9 & - \\
\hline REFERÊECI & -- & $6.000 \mathrm{a}$ & 0 a 300 & $3.000 \mathrm{a}$ & $1.000 \mathrm{a}$ & $150 \mathrm{a}$ & $100 \mathrm{a}$ & 0 a 100 & 0 & - \\
\hline $\mathbf{A}$ & & 17.000 & & 11.500 & 4.800 & 1.350 & 1.250 & & & \\
\hline
\end{tabular}

Apenas sete gatos foram submetidos ao tratamento qumioterápico, sendo que o gato 3 recebeu duas sessões com vincristina $\left(0,6 \mathrm{mg} / \mathrm{m}^{2}\right.$, pela via intravenosa, com intervalo de 11 dias), o gato 4 recebeu uma sessão de vincristina $\left(0,6 \mathrm{mg} / \mathrm{m}^{2}\right.$, pela via intravenosa) e, após sete dias, uma dose de lomustina $\left(40 \mathrm{mg} / \mathrm{m}^{2}\right)$, o gato 6 recebeu, com intervalos de sete dias: vincristina $\left(0,6 \mathrm{mg} / \mathrm{m}^{2}\right.$, intravenosa), doxorrubicina $(1 \mathrm{mg} / \mathrm{kg}$, intravenosa em 20-40 minutos) e lomustina (40 mg/m², via oral). O gato 12 encontra-se em remissão dos sinais clínicos e sem anemia, e em tratamento com o protocolo de Wisconsin-Madison (WM) (VAIL, 2007) modificado a partir da substituição da ciclofosfamida pela lomustina e seguindo a seguinte sequência: lomustina - vincristina doxorrubicina - vincristina, com intervalos de sete dias e proposta de repetição deste ciclo cinco vezes, totalizando 20 sessões de quimioterapia. Os gatos 7, 10 e 11 realizaram o mesmo protocolo e ficaram estáveis por quatro, tendo recidiva no aumento de linfócitos após esse período, e um protocolo de resgate com Citarabina $300 \mathrm{mg} / \mathrm{m}^{2}$ associada a doxorrubicina $1 \mathrm{mg} / \mathrm{kg}$ e dexametasona $1 \mathrm{mg} / \mathrm{kg}$, foi instituído nos gatos 7 e 11 , porém 
vieram a óbito após 4 e 7 dias da aplicação respectivamente. O gato 10 não realizou o protocolo de resgate por opção do tutor (Tabela 3).

Tabela 3 - Bioquímica sérica no momento do diagnóstico da leucemia linfóide aguda em nove gatos

\begin{tabular}{|c|c|c|c|c|c|c|c|c|c|c|}
\hline GATOS & DATA & $\begin{array}{l}\text { URÉIA } \\
\text { mg/dL }\end{array}$ & $\begin{array}{c}\text { CREATI } \\
\text { NINAmg } \\
\text { /dL } \\
\end{array}$ & $\begin{array}{l}\text { ALT } \\
\text { UI/L }\end{array}$ & $\begin{array}{l}\text { AST } \\
\text { UI/L }\end{array}$ & $\begin{array}{c}\text { FA } \\
\text { UI/L }\end{array}$ & $\begin{array}{l}\text { GGT } \\
\text { UI/L }\end{array}$ & $\begin{array}{c}\text { PT } \\
\text { g/dL }\end{array}$ & $\begin{array}{c}\text { Albumina } \\
\text { g/dL }\end{array}$ & $\begin{array}{c}\text { Globulinas } \\
\text { g/dL }\end{array}$ \\
\hline GATO 1 & 06/06/18 & 63,0 & 0,9 & 76,8 & -- & 24,8 & 6,6 & 5,6 & 2,4 & 3,2 \\
\hline GATO 2 & $29 / 01 / 18$ & - & - & - & - & -- & - & - & -- & -- \\
\hline GATO 3 & $22 / 08 / 16$ & - & 1,1 & 29,6 & - & 30,3 & 2,2 & 5,7 & 1,9 & 3,8 \\
\hline GATO 4 & $02 / 04 / 18$ & 57,8 & 1,7 & 90,7 & 59,3 & 90,9 & 4,4 & 5,6 & 2,1 & 3,5 \\
\hline GATO 5 & $22 / 09 / 16$ & 38 & 1,5 & 76,8 & 82 & 66,1 & - & - & -- & -- \\
\hline GATO 6 & $28 / 03 / 17$ & 33 & 1,3 & 225,2 & 377,1 & 55,1 & - & 5,9 & 3 & -- \\
\hline GATO 7 & $04 / 07 / 18$ & 32 & 1,0 & 55 & 39 & 79 & - & 7,3 & 3,7 & 3,6 \\
\hline GATO 8 & $10 / 07 / 18$ & 68 & 1,24 & 93 & 144 & - & 2 & - & - & -- \\
\hline GATO 9 & $30 / 09 / 15$ & 81 & 1,4 & 316,6 & 144,9 & - & 6,4 & 6,2 & 1,8 & 4,4 \\
\hline GATO 10 & $29 / 05 / 19$ & 93 & 1,78 & 133 & 282 & - & 9,2 & - & - & - \\
\hline GATO 11 & $21 / 06 / 19$ & 38,3 & 1,4 & 47,6 & - & 27,2 & 7,2 & 6,4 & 3,2 & 3,2 \\
\hline GATO 12 & $30 / 12 / 19$ & 40,4 & 1,29 & 74 & 74 & - & 6,0 & 6,6 & - & - \\
\hline MÉDIA & -- & 54,45 & 1,32 & 110,75 & 150,28 & 53,34 & 5,5 & 6,16 & 54,45 & 1,32 \\
\hline MEDIANA & -- & 49,1 & 1,3 & 76,8 & 113 & 55,1 & 6,2 & 6,05 & 49,1 & 1,3 \\
\hline DESVIO PADRÃO & -- & 21,478 & 0,271 & 86,036 & 26,657 & 26,657 & 2,484 & 0,592 & 21,478 & 0,271 \\
\hline REFERÊNCIA & -- & $42,8-64,2$ & $0,8-1,8$ & $6-83$ & $26-43$ & $23-93$ & $1,3-5,1$ & $5,4-7,8$ & $2,1-3,1$ & $2,6-5,1$ \\
\hline
\end{tabular}

Transfusão sanguínea foi realizada uma única vez nos pacientes 3 e 7, e duas vezes no gato 8 . O filgrastim foi utilizado, na dose de $5 \mathrm{mcg} / \mathrm{kg}$, pela via subcutânea, apenas no gato 7, que recebeu três doses (sendo duas em dias consecutivos devido a neutropenia grave).

Figura 1 - Esfregaço sanguíneo com a evidenciação de anisocitose eritrocitária e células redondas grandes, mais que 3x o tamanho de uma hemácia, com citoplasma moderado, azulado, com halo claro perinuclear, núcleo redondo, cromatina pontilhada e um a dois nucléolos distintos (linfoblastos), compatível com o diagnóstico de leucemia linfoide aguda (leucêmica)

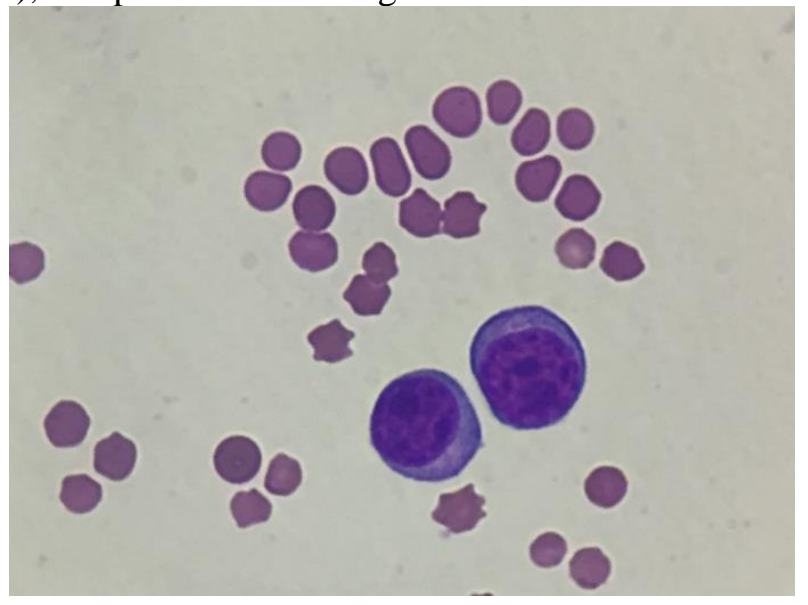


Dos doze gatos relatados, três tiveram perda do acompanhamento, cinco evoluíram para o óbito logo após o diagnóstico e três sobreviveram com qualidade de vida por quatro meses, e apenas um (gato 12) segue em tratamento com quimioterapia, resultando em uma mediana de sobrevida de 16 dias após o diagnóstico da LLA (Figura 2).

Figura 2 - Curva de Kaplan-Meier representando a sobrevida de seis gatos com leucemia linfóide aguda associada à infecção progressiva pelo vírus da leucemia felina, atingindo a mediana aos 16 dias

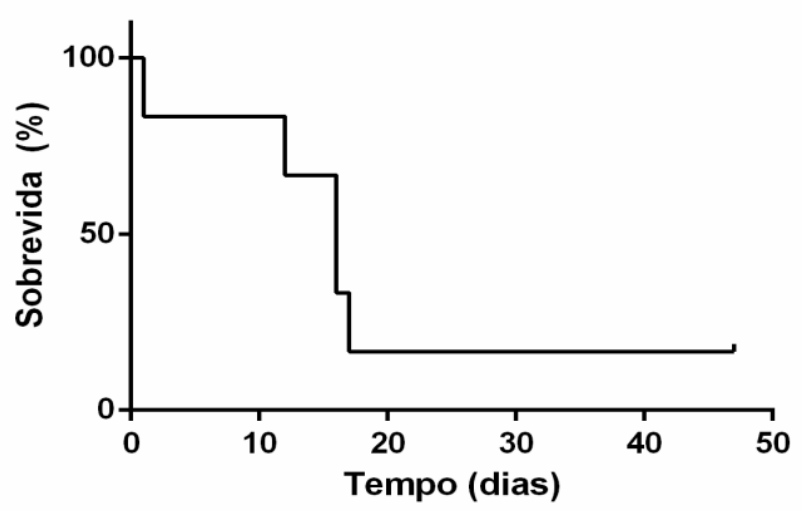

Na Oncologia Veterinária, o resultado mais provável da infecção pelo FeLV é o desenvolvimento de linfomas, com destaque para a apresentação mediastinal, multicêntrica (WEISS et al, 2010) e mesmo, as formas extra-nodais, com acometimento do pericárdio (AMATI et al., 2014), rim, globo ocular, sistema nervoso e região retrobulbar (MARCONATO et al, 2012). Entretanto, conforme demonstrado nessa pesquisa, distúrbios sanguíneos malignos como leucemias também podem ocorrer (PRIHIRUNKIT et al., 2008; GAVAZZA et al., 2012) de forma primária ou secundária ao acometimento da medula óssea por um linfoma (THRALL, 1981).

A maioria dos gatos que desenvolvem LLA apresentam infecção progressiva pelo FeLV (DOBSON et al., 2006), diferente da forma crônica que tem maior incidência em gatos negativos nos testes antigênicos (TEBB et al., 2004). Este foi um dos critérios considerados para o diagnóstico presuntivo de LLA nesse trabalho, já que todos os gatos eram reagentes pelo ensaio de imunoabsorção enzimática (ELISA), que detecta o antígeno p27 no sangue circulante e, portanto, a doença na sua forma progressiva (ALMEIDA et al., 2012). Os kits de triagem apresentam uma sensibilidade de 92 a $94 \%$ e, especificidade de 92 a 99\%, mas em casos de infecções recentes ou regressivas, estes podem fornecer um resultado falso negativo e a Reação em Cadeia da Polimerase (PCR) 
é indicada para a confirmação da presença do vírus no organismo (ARJONA et al., 2007). Por ser uma doença regressiva, o antígeno pode não estar presente no sangue, mas o DNA proviral será detectável em células circulantes (CRAWFOR, 2011). Neste estudo, os animais foram caracterizados como persistentemente virêmicos com o resultado positivo pelo teste rápido e o PCR não se fez necessário.

As informações morfológicas, imunofenotípicas e genéticas moleculares do sangue e medula óssea e infiltração em outros órgãos auxiliam no diagnóstico de leucemia linfoide (WORKMAN \& VERNAU, 2003). História, exame físico e exames laboratoriais são igualmente importantes, os quais foram os principais fatores avaliados nos gatos selecionados para esta pesquisa. A avaliação hematológica de um paciente geralmente fornece a primeira indicação de leucemia, podendo haver leucocitose e/ou redução das demais linhagens celulares, sendo que, em alguns casos pode ocorrer ainda a presença de células leucêmicas anormais nos esfregaços sanguíneos (DOBSON et al., 2006).

O maior estudo retrospectivo foi publicado por Jain (1993), que examinou a medula óssea de 181 gatos com suspeita de leucemia. Foram avaliados os esfregaços medulares para tipos e números de células blásticas e mielóides, monocíticas, e diferenciação eritróide, resultando em $61,4 \%$ dos gatos diagnosticados com leucemias agudas. Outros gatos foram diagnosticados com síndrome mielodisplásica $(21,5 \%)$, eritroleucemia $(17,1 \%)$. Anemia (normocítica ou macrocítica) foi identificada em 91,3\% dos animais no estudo de Jain (1993) e em metade dos gatos do presente estudo (50\%). Tal fato provavelmente ocorre em decorrência da mielofitise, mas pode ocorrer, ainda devido à doença inflamatória, hipoplasia eritróide provocada pelo FeLV ou hemólise imunomediada (HARTMANN, 2011). Ainda no estudo de Jain (1993), em 51,2\% dos gatos foram observados trombocitopenia, uma alteração encontrada de forma mais acentuada nesse trabalho, pois apenas um animal citato se encontrava com o valor de plaquetas dentro dos valores de referência. A trombocitopenia pode ocorrer devido à supressão da medula óssea causado pelo vírus ou pela infiltração da mesma por células neoplásicas, e, ainda, de forma imunomediada (LEVY \& CRAWFORD, 2010).

$\mathrm{Na}$ avaliação do leucograma apenas aproximadamente $20 \%$ dos pacientes com Leucemias agudas apresentaram 30\% de células blásticas em sangue periférico, indicando que $80 \%$ dos gatos necessitaram de avaliação medular para confirmar o diagnóstico (JAIN, 1991). Em outro estudo, apenas 16\% dos gatos com LLA apresentaram linfocitose acentuada (mais de 14.000 céls $/ \mu \mathrm{L}$ ), mas apesar de uma quantidade semelhante de células 
por $\mu \mathrm{L}$ a este estudo, que obteve linfocitose acima de 13.000 céls/ $\mu \mathrm{L}$, o que difere é que $100 \%$ dos animais incluídos neste estudo apresentaram linfocitose acentuada. Já os linfoblastos foram detectados em esfregaços de sangue periférico de $74 \%$ dos pacientes, um número bem maior do que foi observado nos animais deste trabalho $(22,2 \%)$ (WILKINS, 1974).

A LLA foi caracterizada por Gilmore et al. (1964), em um aumento persistente do número absoluto de linfócitos totais no sangue periférico, com uma média de 45.800/uL linfócitos. Essa característica fez-se presente nos animais avaliados nesse estudo, sendo evidenciado o número de linfócitos acima de $80 \%$ em relação ao valor de referência presente na tabela 2. Em casos de suspeita de leucemias linfoides faz-se necessário diferenciar os linfócitos normais dos neoplásicos, e a morfologia linfocitária pode revelar linfócitos pequenos, maduros ou reativos (KELLER et al., 2016). Vários autores consideram um diagnóstico de leucemia aguda quando é observado um aumento de células imaturas (blastos) superior a $20 \%$ no sangue periférico e na medula óssea (HARVEY, 2012; TURINELLI \& GAVAZZA, 2018). Contudo, neste estudo, foram encontrados blastos no sangue de apenas três dos gatos, que representaram os únicos com linfocitose superior a 100.000/ $\mu \mathrm{L}$, podendo indicar quadro mais avançado. A punção de medula óssea não foi realizada devido ao curso rápido da doença, normalmente identificado nas LLA, debilitação dos animais e restrição financeira. A realização desse exame seria, entretanto, de pouco auxílio no diagnóstico e tratamento desses pacientes.

O diagnóstico da leucemia aguda pode ser desafiador, pois a citomorfologia das células blásticas no sangue e na medula óssea podem variar consideravelmente, por isso em seres humanos, foram estabelecidos critérios de classificação e diagnóstico das leucemias, pelo grupo French-American-British (FAB), e os mesmos foram adaptados para a Medicina Veterinária (JAIN et al, 1991). Os critérios são baseados principalmente no número e morfologia das células blásticas no sangue e na medula óssea. Na LLA a transformação de células precursoras resulta em uma proliferação maciça de células indiferenciadas que são incapazes de maturação (JAIN et al., 1991). Na LLC, por sua vez, a transformação tardia de células precursoras resulta em uma superprodução de células maduras e diferenciadas (DOBSON et al., 2006).

Os linfoblastos encontrados no sangue dos gatos 2, 3 e 7 possuíam morfologia semelhante aos citados por Jain et al. (1991), os quais são identificados por apresentarem núcleo redondo a oval com cromatina finamente dispersa ou eucromatina abundante e um 
nucléolo, podendo ter quantidade moderada de citoplasma e cromatina nuclear grosseira. A observação da morfologia celular pode ser útil, mas o diagnóstico definitivo depende do uso de corantes citoquímicos e técnicas de imunofenotipagem, que não puderam ser realizados nessa série de casos (DOBSON et al., 2006). Os corantes citoquímicos são usados para distinguir a leucemia mielóide da linfoide em animais (JAIN et al., 1991).

Os linfoblastos distinguem-se dos mieloblastos por apresentarem coloração negativa em marcadores neutrofílicos como peroxidase, Sudan Black B (SBB) e cloroacetato esterase (JAIN et al, 1991). Da mesma forma, granulócitos e alguns monócitos têm uma reação citoplasmática granular com SBB enquanto os linfócitos não coram com este corante lipofílico (RASKIN, 2010). A atividade fosfatase alcalina (AFA) está presente em subgrupos de linfócitos caninos em alguns casos de linfoma e leucemia linfoide (WELLMAN et al., 1989; MADEWELL et al., 1991; RASKIN \& NIPPER, 1992; GRAVES et al., 1997).

Os neutrófilos não expressam a atividade desse corante, mas monócitos podem ser fracamente positivos enquanto os eosinófilos apresentam fortes reações citoplasmáticas (RASKIN, 2010). Nos últimos anos, o uso paralelo ou combinado de marcadores imunológicos e métodos citoquímicos em células linfocíticas resultaram na demonstração de importantes observações em linfócitos normais e leucêmicos quanto ao padrão e grau de positividade das seguintes enzimas: fosfatase ácida (AcP), anaftil acetato esterase (aNA E) e f3-glucuronidase (f3-GLU).

A reação do ácido periódico de Schiff (APS) tem sido amplamente utilizada para o diagnóstico diferencial de linfoblastos agudos de leucemias mieloblásticas agudas em humanos. A positividade está presente em aproximadamente $50 \%$ dos casos de LLA. As leucemias agudas que não apresentam evidência morfológica de diferenciação granulocítica e que são mieloperoxidase, SBB negativo e não apresentam reação de esterases devem ser classificadas como LLA sempre que apresentem um padrão forte de coloração granular e / ou globular para APS.

A coloração citoquímica melhorou a qualidade do diagnóstico das leucemias e por vezes resultou em uma mudança na interpretação morfológica inicial (GRINDEM et al., 1986). Mas na Medicina (CORDEIRO et al., 2018) e Medicina Veterinária (TASCA et al., 2009; CAMPBELL et al., 2012), a imunofenotipagem por citometria de fluxo (ICF) é o método mais recomendado na identificação, enumeração e caracterização de células leucêmicas imaturas e maduras (BASSO et al., 2001), embora frequentemente este exame 
esteja indisponível nos países em desenvolvimento, conforme na realização deste estudo. No processo de diferenciação e maturação, os linfócitos apresentam antígenos de superfície que podem estabelecer perfis de diferenciação maturativo. As leucemias se desenvolvem durante a expansão clonal de uma célula em determinado estágio maturativo e podem ser classificadas conforme sua origem celular, baseada na expressão antigênica (DAVIDSON et al., 2012). Os linfócitos são um grupo funcionalmente heterogêneo de células que são frequentemente similares em morfologia. A comparação das porcentagens normais facilita a avaliação da linfocitose periférica e a diferenciação de um processo benigno ou reativo, de um processo neoplásico (AVERY \& AVERY, 2007). Os gatos tendem a ter um menor número de células T (25\%) e uma maior porcentagem de células B (aproximadamente 75\%) no sangue periférico e apresentam diferenças significativas relacionadas à idade, raça e possivelmente ao gênero (WORKMAN \& VERNAU, 2003).

A avaliação de lesões microscópicas e imunofenotipagem antes do teste de clonalidade fazem-se necessário para facilitar a identificação do tipo de neoplasia (MIYAMOTO et al, 1996). Os ensaios de clonalidade molecular são comumente utilizados para avaliar proliferações linfoides atípicas, mistas ou maduras, demonstrando a diversidade do arranjo gênico do receptor de antígeno linfocitário e diferenciando as proliferações linfoides reativas das neoplásicas. Além disso, pode ser utilizado para rastrear clones neoplásicos ao longo do tempo ou através de locais anatômicos. Os ensaios de clonalidade molecular não são testes independentes, mas úteis em conjunto com a avaliação clínica, morfológica e imunofenotípica. Este método é espécie específico e, na Medicina Veterinária, está disponível para cães, gatos (VAN DONGEN et al., 2003) e cavalos (COOPER et al., 2018), apesar de não ser um exame oferecido em laboratórios comerciais em todos os países. Embora esses métodos sejam ideais para a confirmação diagnóstica da LLA, não foram possíveis de serem realizados devido À indisponibilidade das técnicas e rápida evolução das LLA em gatos com infecção progressiva pelo FeLV, justificando um rápido diagnóstico presuntivo, baseado no status retroviral, bicitopenias e inversão grave de neutrófilos e linfócitos, conforme demonstrado na tabela 2.

Para LLC, o tratamento é recomendado apenas nos casos sintomáticos, baseando-se no uso da prednisolona em associação ao clorambucila (DOBSON et al., 2006). Campbell et al. (2012) reuniu 18 casos de gatos diagnosticados com LLC. Dentre esses animais, 17 iniciaram o tratamento no momento do diagnóstico e um gato só iniciou o tratamento após 6,8 meses por desenvolver linfoma intestinal. O protocolo estipulado 
para 16 gatos (89\%) foi a associação de clorambucila e prednisolona, sendo que quatro destes também receberam vincristina na primeira semana. Outros dois gatos foram tratados com o protocolo L-CHOP, consistindo em L-asparaginase, ciclofosfamida, doxorrubicina e vincristina, combinado ao clorambucil ou prednisolona. A mediana de sobrevida para os 17 gatos que tiveram acompanhamento foram 14,4 meses (variação: 0,9 a 25,3 meses). A mediana de sobrevida para os 15 gatos que responderam ao tratamento foi de 17,7 meses. Onze dos 17 (65\%) gatos ficaram vivos por um ano, e 2/17 (12\%) ficaram vivos por dois anos.

Para as LLA, entretanto, observa-se um prognóstico muito pior, particularmente naqueles gatos com infecção progressiva pelo FeLV. Existem poucos relatos de tratamento de LLA em felinos. Por se tratar de uma patologia muito agressiva, a maioria dos pacientes vêm a óbito antes de obter um diagnóstico definitivo, sem que exista tempo hábil para instituição do tratamento quimioterápico, ou até mesmo são eutanasiados devido ao quadro grave que, muitas vezes impossibilita o tratamento sem a realização de transfusões sanguíneas (PRIHIRUNKIT et al., 2008). Embora não existam estudos publicados comparando diferentes tipos de protocolos quimioterápicos e seus resultados, alguns protocolos de quimioterapia podem ser adotados, geralmente, os mesmo utilizados para tratamento de linfomas de alto grau, envolvendo a combinação de fármacos (TAYLOR et al, 2009; DUTELLE et al., 2012; CAMPBELL et al., 2012; BOUZOURAA et al., 2018), a exemplo do protocolo de Wisconsin-Madison modificado (ciclofosfamida, doxorrubicina, vincristina e prednisolona) (TAYLOR et al., 2009; AMATI et al., 2014), o qual nos baseamos para o tratamento dos gato $7,10,11$ e 12, apenas substituindo a ciclofosfamida pela lomustina.

No estudo de Taylor et al. (2009), 149 gatos foram diagnosticados com linfoma extranodal, sendo a maioria (69 gatos) com localização nasal, 35 renal, 15 em sistema nervoso central, laríngea em 11 e 19 gatos com formas mistas. Apenas 7,4\% desses animais eram FeLV ou FIV positivos. Os gatos foram divididos nos seguintes grupos de tratamento: prednisolona isolada, protocolos baseados em COP (ciclofosfamida, vincristina e prednisolona), Wisconsin-Madison (vincristina, L-asparaginase, ciclofosfamida, prednisolona, doxorrubicina e metotrexato) e outros. Não houve diferença estatística na resposta ao tratamento entre os locais acometidos $(p=0,445)$. A taxa de remissão foi de $92,4 \%$ no grupo COP e $72 \%$ no grupo no grupo tratado com o protocolo modificado da Universidade de Wisconsin $(\mathrm{p}=0,015)$, entretanto, 
considerando-se apenas os gatos que atingiram remissão completa, observou-se maior sobrevida naqueles tratados com o protocolo de Wisconsin-Madison (563 dias) em comparação com os gatos tratados apenas com COP (239 dias), com $p=0,037$. Da mesma forma, o uso de glicocorticóides antes do tratamento, comprometeu a sobrevida desses pacientes. A L-asparaginase, entretanto, encontra-se indisponível em alguns países, apresenta elevado custo e os pacientes do estudo de Taylor et al. (2009) apresentam um perfil clínico diferenciado dos gatos deste estudo. O gato 7 deste estudo encontra-se com melhora dos sinais clínicos e ainda em tratamento, o que sugere que este seja um protocolo útil no tratamento de LLA em felinos.

Por ser uma neoplasia fatal e intimamente associada ao FeLV, a melhor forma de prevenir o desenvolvimento da LLA é evitar a infecção (LEVY et al., 2008). O vírus é envelopado tornando-o muito sensível ao meio ambiente, sendo facilmente eliminado com o uso de detergentes e desinfetantes (HARTMANN, 2006; FENNER, 2011). O diagnóstico precoce de gatos FeLV positivos permite a implantação de ações para prevenir a disseminação da infecção pela segregação e otimização dos cuidados de saúde dos gatos infectados (CRAWFORD, 2011). Esses gatos devem ser monitorados com a realização de exame físico, hemograma completo, perfil bioquímico, urinálise e radiografia torácica a cada 6 a 12 meses, e devem ser castrados (LUTZ et al., 2009). Testar gatos suscetíveis permitirá a introdução de um programa de vacinação para os animais em risco, a fim de reduzir a propagação do vírus (LUTZ et al., 2009). A vacinação de gatos negativos com vírus inativado é o meio mais eficaz de prevenção para gatos que se encontram sob risco, em áreas endêmicas e/ou possuem acesso ao ambiente extradomiciliar.

\section{CONCLUSÃO}

Os doze gatos avaliados apresentaram características compatíveis com um quadro leucêmico agudo, tendo a necessidade de instituição terapêutica rápida mesmo não se obtendo um diagnóstico definitivo. O prognóstico é desfavorável, mas quatro gatos resultaram em melhora clínica realizando o tratamento com o protocolo WisconsinMadison modificado, chegando a um período de sobrevida de 120 dias, o que sugere que este seja um protocolo útil no tratamento de LLA em felinos.

A identificação de linfoblastos não é freqüente nas LLA em gatos, exceto nas linfocitoses exageradas, que podem indicar quadros mais avançados da doença. 
A presença do FeLV é um fator significativo para um diagnóstico presuntivo da LLA, podendo ser considerado a principal causa de quadros leucêmicos agudos em gatos jovens.

\section{REFERÊNCIAS}

ALMEIDA, N.R. et al. Prevalence of feline leukemia virus infection in domestic cats in Rio de Janeiro. Journal of Feline Medicine and Surgery. 2012. 4p.

AMATI, M.; VENCO, L.; ROCCABIANCA, P.; SANTAGOSTINO, S. F.; BERTAZZOLO, W. Pericardial lymphoma in seven cats. Journal of Feline Medicine and Surgery, v.16, n.6, p.507-512, 2014.

ARJONA, A.; BARQUERO, N.; DOMÉNECH, A. et al. Evaluation of a novel nested pcr for the routine diagnosis of feline leucemia virus (felv) and feline immunodeficiency vírus (fiv). Journal Feline Med Surg, v.9, p.14-22, 2007.

AVERY, A.C., AVERY, P.R. Determining the Significance of Persistent Lymphocytosis. In ALISSON, R.W., MEINKOTH, J.H. Veterinary Clinics Small Animal Pratice, Guest Editors, 2007. p. 267-282.

BASSO, G.; BULDINI, B.; DE ZEN, L, et al. New methodological approaches for immunophenotyping acute leukemias. Haematologica. v.86, p.675-692, 2001.

BOUZOURAA, T.; RANNOU, B.; SAYAG, D.; PONCEC, F.; SEGARDD, E.; BELLUCO, S. et al. Large granular leukemia with concurrent central nervous system and articular infiltration in a cat. Revue vétérinaire clinique, 2018.

CAMPBELL, M. W.; HESS, P. R.; WILLIAMS L. E. Chronic lymphocytic leukaemia in the cat: 18 cases (2000-2010). Blackwell Publishing Ltd, Veterinary and Comparative Oncology, 2012.

CARMICHAEL, K. P.; BIENZLE, D.; MCDONNEL, J. J. FelineLeukemiaVirusassociated Myelopathy in Cats. Vet Pathol. v.39, p.536-545, 2002.

CORDEIRO, S. V.; RIBEIRO FILHO, A. C.; PAREDES-GAMERO, E. J. Avaliação da expressão e funcionalidade dos receptores purinérgicos em células leucêmicas. Revista Científica UMC, 2018.

COOPER, C. J.; KELLER, S. M.; ARROYO, L. G.; HEWSON, J.; KENNEY, D.; BIENZLE, D. Acute Leukemia in Horses. Veterinary Pathology, v.55, n.1, p.159-172. 2018 .

CRAWFOR, C. Progressos no diagnóstico de infecções retrovirais. In AUGUST, J.R. Medicina Interna De Felinos. 6.ed. Rio de Janeiro: Elsevier, 2011. p.53-77.

CRAWFORD, C. Progressos no diagnóstico de infecções retrovirais. In Medicina Interna de Felinos. 53-62. 2011. 
DAVIDSON, B.; DONG, H.P.; BEMER, A.; RISBERG, B. Diagnostic and research applications of flow cytometry in cytopathology. Diagn Cytopathol. v.40, n.6, p.525$535,2012$.

DOBSON, J.V.; VILLIERS, E.; MORRIS, J. Diagnosis and management of leukaemia in dogs and cats. Practice, v.28, p.22-31, 2006.

DUTELlE, A. L.; BULMAN-FLEMING, J. C.; LEWIS, C. A.; ROSENBERG, M. P. Evaluation of lomustine as a rescue agent for cats with resistant lymphoma. Journal of Feline Medicine and Surgery, v.14, n.10, p.694-700, 2012.

FENNER, S. Veterinary Virology. Academic Press, London, v.4, p.491-505, 2011.

GAVAZZA, A.; TURINELLI, V.; LUBAS, G. A. Retrospective study of incidence and classification in feline bone marrow cytological examination. Proceedings of the XIV Congress European Society of Veterinary Clinical Pathology; July 3-7 2012 Ljubljana, Slovenia. Anais... p.168-169, 2012.

GILMORE, C.E.; GILMORE, V. H.; JONES, T. C. Reticuloendotheliosis, a Myeloproliferative Disorder of Cats: A Comparison with Lymphocytic Leukemia. Path. vet., v.1, p.161-183, 1964.

GRAVES, T.K.; SWENSON, C.L.; SCOTT, M.A. A potentially misleading presentation and course of acute myelomonocytic leukemia in a dog. J Am Anim Hosp Assoc. v.33, p.37-41, 1997.

GRINDEM, C.B.; STEVENS, J.B; PERMAN, V. Cytochemical reactions in cells from leukemic dogs. Vet Pathol. v.23, 103-109, 1986.

HARTMANN, K. Infecção pelo vírus da leucemia felina. In GREENE, C.E. Doenças infecciosas em cães e gatos. 4 ed. Roca. Rio de Janeiro 2015. p. 113-143.

HARTMANN, K. Clinical aspects of feline immunodeficiency and feline leukemia virus infection. Veterinary Immunology and Immunopathology. v.143, p.190- 201, 2011.

HARTMANN, K. Feline leukemia virus infection. In: Greene, C.E. Infectious disease of the dog and cat. 3.ed. Georgia: Elsevier. v.13, p.105-131, 2006.

HARVEY, J.W. Disorders of bone marrow. In: Harvey JW (ed). Veterinary hematology. A diagnostic guide and color atlas. Philadelphia, PA: Elsevier Saunders, 2012, pp 260-318.

JAIN, N. C. et al. Proposed Criteria for Classification of Acute Myeloid Leukemia in Dogs and Cats. Veterinary Clinical Pathology. v.20, n.30, p.63, 1991.

JARRETT, W.F. et al. A virus-like particle associated with leukaemia (lymphosarcoma). Nature, v.202, p.567-568, 1964.

KELLER, S. M.; VERNAU, W.; MOORE, P. F. Clonality Testing in Veterinary Medicine: A Review With Diagnostic Guidelines. Veterinary Pathology, v.53, n.4, p.711-725, 2016. 
LEVY, J.; CRAWFORD, C.; HARTMANN, K. et al. American of feline practitioners' feline retrovirus management guidelines. Journal Feline Med Surg. v.10, p.300-316, 2008 .

LEVY, J. K.; CRAWFORD, P. C. Feline Leukemia Virus. In: ETTINGER, S. J., Textbook of Veterinary Internal Medicine Expert Consult. 7 ed. St. Louis: Elsevier, 2010. Cap.212, p.935-939.

LUTZ, H.; ADDIE, D.; BELAK, S. et al. Feline leukaemia ABCD guidelines on prevention and management. J Feline Med Surg, v.11, p.565-574, 2009.

MADEWELL, B.R.; JAIN, N.C.; MUNN, R.J. Unusual cytochemical reactivity in canine acute myeloblastic leukemia. Comp Haematol Int. v.1, p.117-120, 1991.

MARCONATO, L.; ROSSI, F.; BETTINI, G.; COMAZZI, S.; BONFANTI, U. AND BUCHHOLZ, J. Linfoma. In: MARCONATO L AND AMADORI D (eds). Oncologia medica veterinaria e comparata. 1 st ed. Milan: Poletto editore, 2012, pp 759-817

MIYAMOTO, T.; HACHIMURA, H.; AMIMOTO, A. A. case of megakaryoblastic leukaemia in a dog. J Vet Med Sci. v.58, p.177-179, 1996.

PRIHIRUNKIT, K.; NARKKONG, N.; APIBAL, S. Acute monoblastic leukemia in a FeLV-positive cat. J. Vet. Sci. v.9, n.1, p.109-111, 2008.

RASKIN, R.E. Cytochemical staining. In: Weiss DJ, Wardrop KJ, eds. Schalm's Veterinary Hematology, 6th ed. Ames, IA: Wiley-Blackwell; 2010. p.1141-1156.

RASKIN, R.E; NIPPER, M.N. Cytochemical staining characteristics of lymph nodes from normal and lymphomaaffected dogs. Vet Clin Pathol. v.21, p.62-67, 1992.

TASCA, S.; CARLI, E.; CALDIN, M., et al. Hematologic abnormalities and flow cytometricimmunophenotyping results in dogs with hematopoietic neoplasia: 210 cases (2002-2006). Vet ClinPathol, v.38, 2009.

TAYLOR, S.S.; GOODFELLOW, M.R.; BROWNE, W.J. et al. Feline extranodal lymphoma: response to chemotherapy and survival in 110 cats. J. Small Anim Pract, v.50, p.584-589, 2009.

TEBB, A.J., CAVE, T., BARRON, R. et al. Diagnosis and management of B cell chronic lymphocytic leukaemia in a cat. Vet Rec, v.154, p.430- 433, 2004.

TURINELLI, V. \& GAVAZZA, A. Retrospective study of 152 feline cytological bone marrow examinations: preliminar classification and ranges. Journal of Feline Medicine and Surgery. P.1-11, 2018.

VAIL, D. M. Feline lymphoma and leukemia. In: Withrow SJ and Vail D (eds). Withrow \& MacEwen's small animal clinical oncology. 4th ed. St Louis, MO: SaundersElsevier, 2007, pp 733-756.

VAN DONGEN, J. J.; LANGERAK, A. W.; BRUGGEMANN, M., et al. Design and standardization of PCR primers and protocols for detection of clonal immunoglobulin and 
T-cell receptor gene recombinations in suspect lymphoproliferations: report of the BIOMED-2 Concerted Action BMH4-CT98-3936. Leukemia, v.17, p.2257-2317, 2003.

WEISS, A. T. A. et al. Prevalence of feline leukaemia provirus DNA in feline lymphomas. Journal of Feline Medicine and Surgery. V.12, p.929-935, 2010.

WELLMAN, M.L. A practical guide to leukemia in dogs and cats. Columbus, $\mathrm{OH}$, USA. 2015. 5p.

WELLMAN, M.L.; COUTO, C.G.; STARKEY, R.J.; ROJKO, J.L. Lymphocytosis of large granular lymphocytes in three dogs. Vet Pathol.; v.26:, n.158-163, 1989.

WILKINS, R. J. Morphologic features of feline peripheral blood lymphocytes. J. Am. Anim. Hosp. Assoc., v.10, p.362-366, 1974.

WORKMAN, H.C.; VERNAU, W.; SCHMIDT, P.S.; ROCCABIANCA, P.; MOORE, P.F.; SHELLY, S.; RUEHL, W. Chronic lymphocytic leukemia in cats is primarily a T helper cell disease. Presented at the 55th Annual Meeting of the American College of Veterinary Pathologists, Orlando, November 13-17, 2004.

WORKMAN, H.C. \& VERNAU, W. Chronic lymphocytic leukemia in dogs and cats: the veterinary perspective. Vet Clin Small Anim, v.33, p.1379-1399, 2003. 